\title{
Gait Disturbances in Dystrophic Hamsters
}

\author{
Thomas G. Hampton, ${ }^{1}$ Ajit Kale, ${ }^{1}$ Ivo Amende, ${ }^{2}$ Wenlong Tang, ${ }^{1}$ Scott McCue, ${ }^{1}$ \\ Hemmi N. Bhagavan, ${ }^{3}$ and Case G. VanDongen ${ }^{3}$
}

\author{
${ }^{1}$ Mouse Specifics, Inc., Boston, MA 02109, USA \\ ${ }^{2}$ Beth Israel Deaconess Medical Center, Harvard Medical School, Boston, MA 02215, USA \\ ${ }^{3}$ Bio Breeders, Inc., Watertown, MA 02472, USA
}

Correspondence should be addressed to Thomas G. Hampton, science@mousespecifics.com

Received 6 October 2010; Accepted 8 November 2010

Academic Editor: Oreste Gualillo

\begin{abstract}
Copyright (C) 2011 Thomas G. Hampton et al. This is an open access article distributed under the Creative Commons Attribution License, which permits unrestricted use, distribution, and reproduction in any medium, provided the original work is properly cited.
\end{abstract}

\begin{abstract}
The delta-sarcoglycan-deficient hamster is an excellent model to study muscular dystrophy. Gait disturbances, important clinically, have not been described in this animal model. We applied ventral plane videography (DigiGait) to analyze gait in BIO TO-2 dystrophic and BIO F1B control hamsters walking on a transparent treadmill belt. Stride length was $\sim 13 \%$ shorter $(P<.05)$ in TO-2 hamsters at 9 months of age compared to F1B hamsters. Hindlimb propulsion duration, an indicator of muscle strength, was shorter in 9-month-old TO-2 $(247 \pm 8 \mathrm{~ms})$ compared to F1B hamsters $(272 \pm 11 \mathrm{~ms} ; \mathrm{P}<.05)$. Braking duration, reflecting generation of ground reaction forces, was delayed in 9-month-old TO-2 (147 $\pm 6 \mathrm{~ms})$ compared to F1B hamsters $(126 \pm 8 \mathrm{~ms}$; $P<.05)$. Hindpaw eversion, evidence of muscle weakness, was greater in 9 -month-old TO- 2 than in F1B hamsters $\left(17.7 \pm 1.2^{\circ}\right.$ versus $\left.8.7 \pm 1.6^{\circ} ; P<.05\right)$. Incline and decline walking aggravated gait disturbances in TO-2 hamsters at 3 months of age. Several gait deficits were apparent in TO-2 hamsters at 1 month of age. Quantitative gait analysis demonstrates that dystrophic TO-2 hamsters recapitulate functional aspects of human muscular dystrophy. Early detection of gait abnormalities in a convenient animal model may accelerate the development of therapies for muscular dystrophy.
\end{abstract}

\section{Introduction}

Muscular dystrophy includes loss of muscle strength and muscle mass and leads to gait disturbances resulting in compensatory kinematic and postural adaptation [1-3]. Eventually, patients lose their ability to stand upright and walk. Clinical gait analysis of subjects with muscular dystrophy is widely used to test the efficacy of new drugs because there are few reliable methods to determine function in muscular dystrophy [1]. Histopathological studies of animal models, including the delta-sarcoglycan-deficient dystrophic hamster, have played an important role in our understanding and treatment of muscular dystrophy [4]. Functional phenotypic evidence, however, of restoration of muscle strength with therapy in animal models, is becoming increasingly important in preclinical drug development [5-9]. A recent study of canine muscular dystrophy accounted for the slower walking speed in dystrophic subjects to more accurately quantify the kinematics of pathologic gait during overground walking [10]. Treadmill gait analysis provides the opportunity to have all subjects walk at the same speed to rule out differences in walking speed as being the most important confounder in the interpretation of gait disturbances. Treadmill gait analysis has recently been applied to the characterization of mouse models of amyotrophic lateral sclerosis [11, 12], rat models of nerve injury [13, 14], and canine arthritis [15]. Quantitative kinematic gait analysis in a small animal model of muscular dystrophy, however, has not yet been reported. We, therefore, performed treadmill gait analysis in the BIO TO-2 strain of myopathic hamsters to fully characterize their posture and kinematics during walking. The BIO TO-2 [TO-2] hamster, with a deletion in the delta-sarcoglycan gene, is a widely studied animal model of muscular dystrophy [16-20]. These animals show pathological signs of muscular dystrophy, including elevated serum creatine kinase and central nucleation and necrosis of muscle fibers. We compared gait in the myopathic hamsters to the gait in healthy $\mathrm{BIO}$ F1B [F1B] control hamsters 


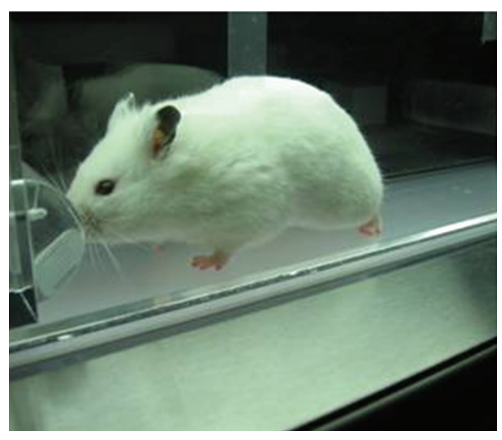

(a)
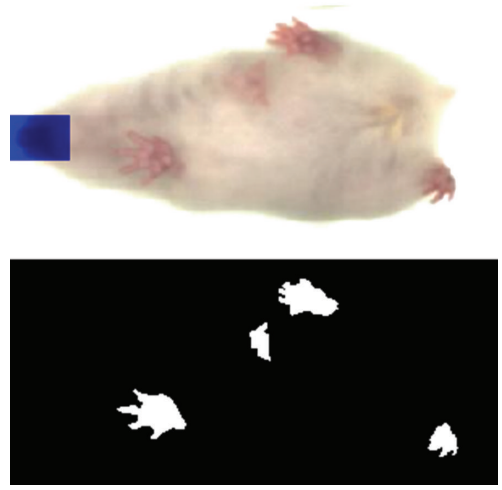

(b)

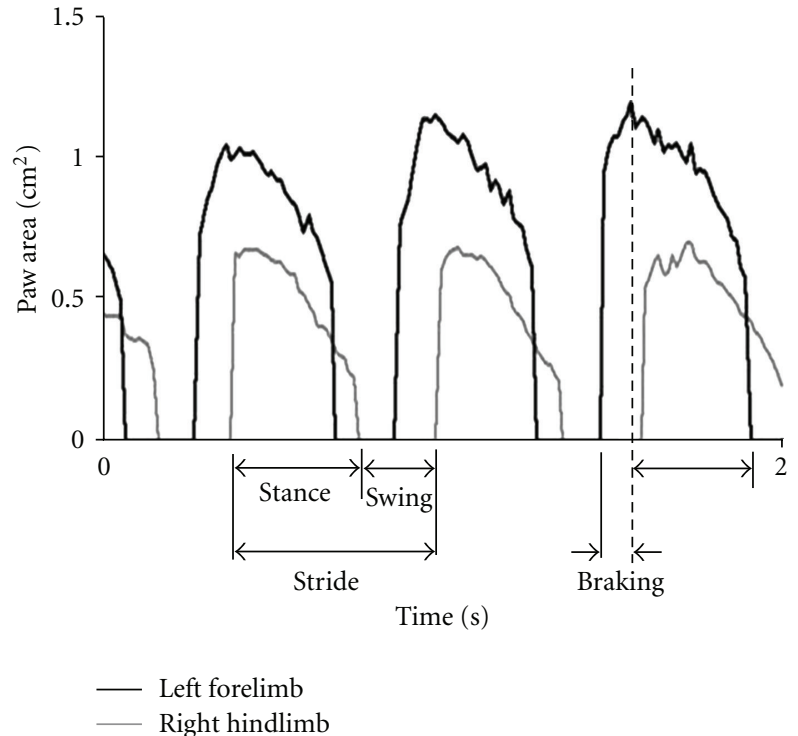

(c)

FIGURE 1: (a) Lateral view of a 9-month-old TO-2 dystrophic hamster walking on DigiGait transparent treadmill belt. The animal walks within an adjustable polycarbonate housing to accommodate a range of animal sizes walking or running at a range of walking speeds ( 0 to $100 \mathrm{~cm} / \mathrm{s}$ ). (b) Individual color image (top) from a digital video recording of the underside of a walking hamster, representing one instance in time. A digital mask was placed over the snout, based on the symmetry and direction of the animal, to prevent the snout from being misinterpreted as a paw. (Bottom) DigiGait software subtracts from each image the pixels that do not match the color of the paws and converts the images to binary, resulting in digital paw prints of the walking hamster. (c) Representative dynamic gait signals of the left forelimb and right hindlimb of a hamster walking at a speed of $16 \mathrm{~cm} / \mathrm{s}$. Durations of stance, swing, and stride are indicated for the right hindlimb. Durations of propulsion and braking are indicated for the left forelimb.

and found several functional indices that significantly and consistently deviate beginning early in life. The method described in this report provides quantitative functional metrics of gait associated with sarcoglycan deficiency in a readily available animal model.

\section{Methods}

2.1. Animals. Male BIO F1B control and BIO TO-2 dystrophic hamsters were obtained from Bio Breeders, Inc., Fitchburg, MA. Handling and care of hamsters were consistent with federal guidelines and approved institutional protocols.

2.2. Gait Dynamics. Gait dynamics were recorded using ventral plane videography, as previously described [21, 22]. Briefly, we devised a motor-driven treadmill with a transparent treadmill belt [DigiGait Imaging System, Mouse Specifics, Inc., Quincy, MA]. A high-speed digital video camera was positioned below the transparent belt to focus on the ventral view of subjects walking atop of the belt.
An acrylic compartment, $\sim 7 \mathrm{~cm}$ wide by $\sim 30 \mathrm{~cm}$ long and adjustable for length and width, was mounted on top of the treadmill to maintain the hamsters within the view of the camera. Figure 1(a) depicts a 9-month-old TO-2 hamster walking on the treadmill belt within the acrylic compartment. Digital video images of the underside of hamsters were recorded at $\sim 125$ frames per second. Each image represents $\sim 8 \mathrm{~ms}$; the paw area indicates the temporal placement of the paw relative to the treadmill belt. The color images (Figure 1(b), top panel) were converted to their binary matrix equivalents (Figure 1(b), bottom panel) and the areas of the approaching or retreating paws relative to the belt and camera were calculated throughout each stride. The plotted area of each digital paw print (paw contact area) imaged sequentially in time provides a dynamic gait signal, representing the temporal record of paw placement relative to the treadmill belt (Figure 1(c)). Each gait signal for each limb comprises a stride duration which includes the stance duration when the paw of a limb is in contact with the walking surface, plus the swing duration when the paw of the same limb is not in contact with 
TABle 1: Gait dynamics in 9-month-old F1B control hamsters and delta-sarcoglycan-deficient TO-2 dystrophic hamsters walking on a treadmill belt at a speed of $16 \mathrm{~cm} / \mathrm{s}$.

\begin{tabular}{lcc}
\hline Gait index & F1B $(n=9)$ & TO-2 $(n=14)$ \\
\hline Stride length $(\mathrm{cm})$ & $8.0 \pm 0.2$ & $7.1 \pm 0.1^{*}$ \\
Stride frequency $(\mathrm{Hz})$ & $2.0 \pm 0.1$ & $2.3 \pm 0.1^{*}$ \\
Stride duration $(\mathrm{ms})$ & $503 \pm 7$ & $443 \pm 4^{*}$ \\
\% Stance & $72.4 \pm 0.5$ & $74.8 \pm 0.4^{*}$ \\
\% Swing & $27.6 \pm 0.5$ & $25.2 \pm 0.4^{*}$ \\
Forelimb stance width & $2.4 \pm 0.1$ & $2.1 \pm 0.1^{*}$ \\
Forelimb stride length CV $(\%)$ & $17.6 \pm 1.6$ & $23.6 \pm 1.4^{*}$ \\
Hindlimb stance width $(\mathrm{cm})$ & $3.8 \pm 0.1$ & $3.9 \pm 0.1$ \\
Hindlimb paw placement angle $\left(^{\circ}\right)$ & $8.7 \pm 1.6$ & $17.7 \pm 1.2^{*}$ \\
\hline
\end{tabular}

Data are means $\pm \mathrm{SE} ; * P<.05$, compared to $\mathrm{F} 1 \mathrm{~B}$ control hamsters.

the walking surface. Stance duration was further subdivided into braking duration (increasing paw contact area over time) and propulsion duration (decreasing paw contact area over time) (Figure 1(c)).

Stride frequency was calculated from the number of gait signals over time. Stride length was calculated from the following equation: speed $=$ stride frequency $\times$ stride length. Stance widths and paw placement angles at full stance were obtained by fitting ellipses to the paws and determining the centers, vertices, and major axes of the ellipses. Forelimb and hindlimb stance widths were calculated as the perpendicular distance between the major axis of the left and right fore paw images and between the major axis of the left and right hindpaw images during peak stance. Paw placement angle was calculated as the angle that the long axis of a paw makes with the direction of motion of the animal during peak stance. Gait data were collected and pooled from both the left and right forelimbs, and the left and right hindlimbs.

Measures of stride-to-stride variability (gait variability) for stride length and stance width were determined as the standard deviation and the coefficient of variation $(\mathrm{CV})$. The standard deviation reflects the dispersion about the average value for a parameter. $\mathrm{CV}$, expressed as a $\%$, was calculated from the following equation: $100 \times$ standard deviation/mean value.

Each hamster was allowed to explore the treadmill compartment for $\sim 1$ minute to acclimatize it to the apparatus. There are few data on hamsters walking on motorized treadmills. We therefore randomly selected TO-2 and F1B hamsters and subjected them to a range of walking speeds. We selected $16 \mathrm{~cm} / \mathrm{s}$ for the 3-month- and 9-month-old hamsters since most animals walked comfortably at this speed and it was sufficiently fast to prevent the hamsters from rearing or turning around during videography. We selected a walking speed of $25 \mathrm{~cm} / \mathrm{s}$ for the more active 1-monthold hamsters. We recorded $\sim 3$ seconds of video images for each hamster walking at a speed of $16 \mathrm{~cm} / \mathrm{s}$ to provide more than 7 sequential strides. Only video segments of hamsters walking with a regularity index of $100 \%$ [23] were used for image analysis. For incline and decline walking, the treadmill, walking compartment, and camera system were pitched at

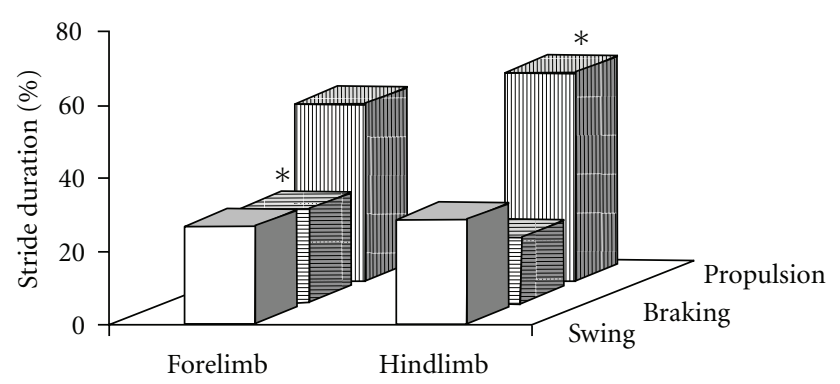

FIGURE 2: (a) The relative contributions of swing, braking, and propulsion to the stride duration of forelimbs and hindlimbs in 9month-old F1B control hamsters walking at $16 \mathrm{~cm} / \mathrm{sec}$. ${ }^{*} P<.05$, forelimbs versus hindlimbs.

an angle so that the animals walked up an incline of $\sim 15^{\circ}$ or down a decline of $\sim 15^{\circ}$, dependent on the direction of the treadmill belt. The angle of treadmill incline and decline was based on published protocols $[8,16,24]$. The treadmill belt was wiped clean between studies if necessary.

2.3. Statistics. Data are presented as means \pm SE. ANOVA was used to test for statistical differences among TO-2 and F1B hamsters at each age. When the $F$-score exceeded $F_{\text {critical }}$ for $\alpha=0.05$, we used post-hoc unpaired Student's twotailed $t$-tests to compare group means. Gait indices between forelimbs and hindlimbs within groups were compared using paired Student's two-tailed $t$-tests. Differences were considered significant with $P<.05$.

\section{Results}

3.1. Gait Dynamics in Hamsters. The ventral view of a 9-month-old healthy F1B control hamster walking on a transparent treadmill belt is shown in Video 1 (Video 1, available as supplemental material). Gait indices for adult F1B hamsters are summarized in Table 1. F1B hamsters $(n=9)$ walked $\sim 2$ steps every second, completed one stride within $\sim 500 \mathrm{~ms}$, and traversed $\sim 8 \mathrm{~cm}$ with each step walking at a speed of $16 \mathrm{~cm} / \mathrm{s}$. The contributions of stance and swing duration to stride duration were $\sim 75 \%$ (stance/stride) and $\sim 25 \%$ (swing/stride).

Differences in the posture and gait dynamics of the forelimbs and hindlimbs were quantified. Forelimb stance width was significantly narrower than hindlimb stance width $(2.4 \pm 0.1 \mathrm{~cm}$ versus $3.8 \pm 0.1 \mathrm{~cm}, P<.05)$. Stance width variability $(\mathrm{CV} \%)$ of hindlimbs was lower than that of forelimbs in 9-month-old F1B hamsters walking at a speed of $16 \mathrm{~cm} / \mathrm{s}$. Figure 2 illustrates the relative contributions of swing, stance, braking, and propulsion to the stride duration of forelimbs and hindlimbs in 9-month-old F1B hamsters. Swing duration of the forelimbs was slightly longer than of the hindlimbs. The braking phase was greater in forelimbs than in hindlimbs $(34.3 \pm 2.1 \%$ versus $24.8 \pm 2.3 \%, P<.05)$, and the propulsion phase was greater in hindlimbs than in forelimbs $(75.2 \pm 2.3 \%$ versus $65.6 \pm 2.1 \%, P<.05)$ with 


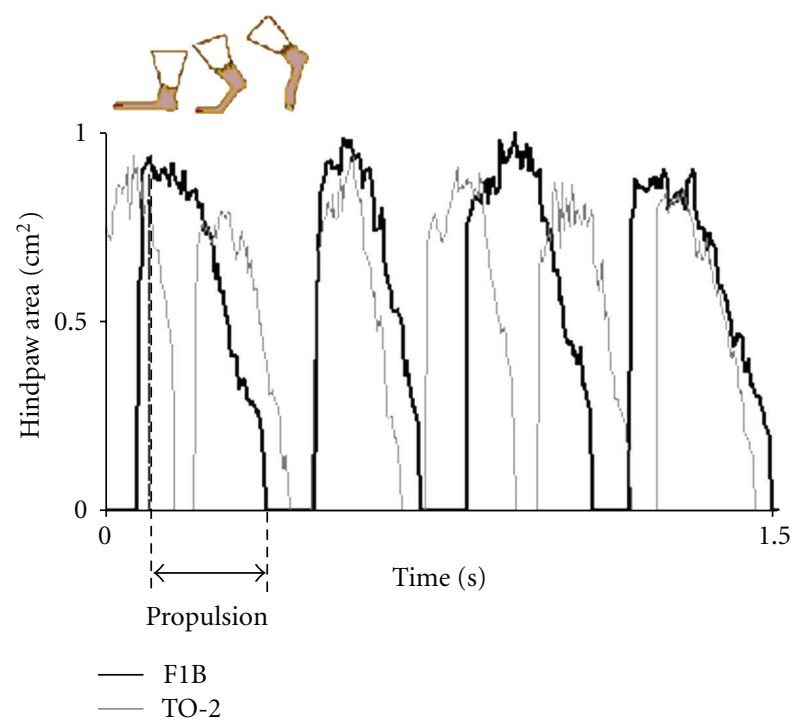

(a)
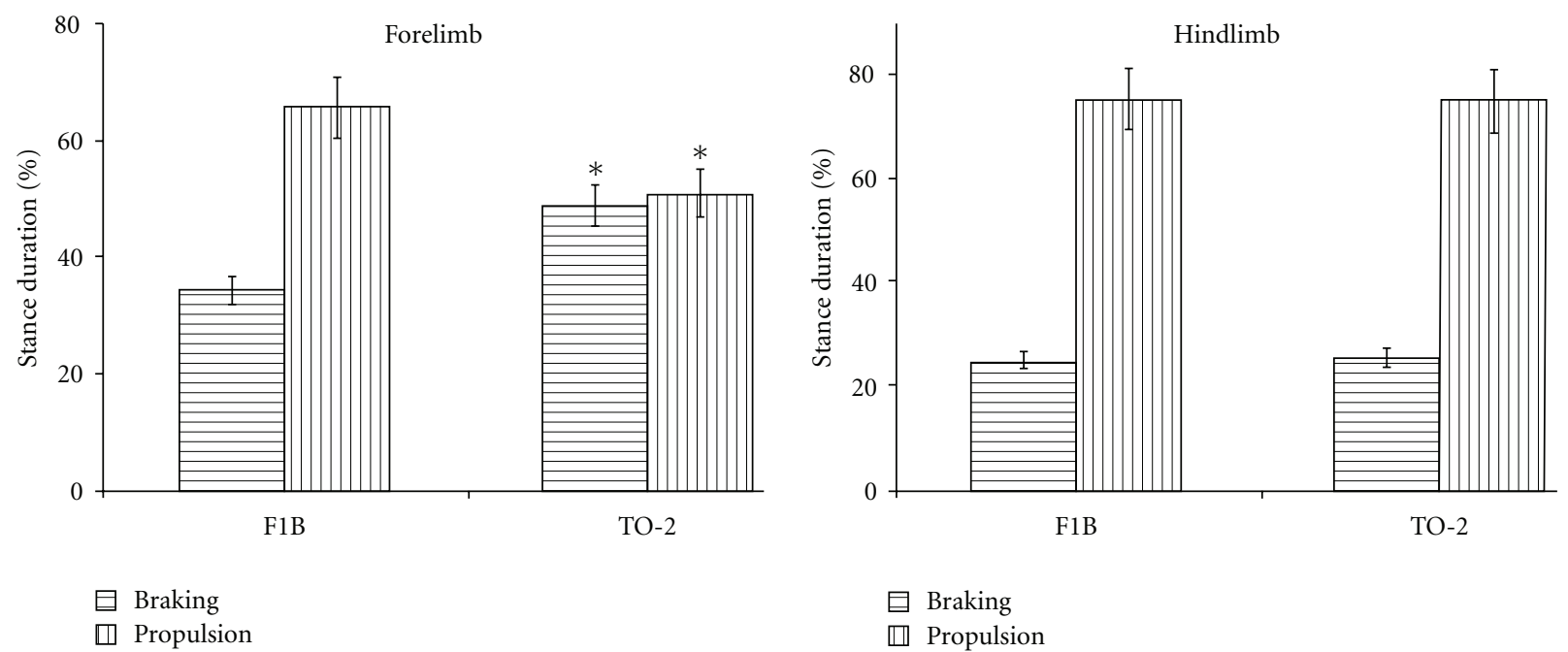

(b)

FIgURE 3: (a) Gait signal of the left hindlimb of a TO-2 hamster superimposed over the gait signal of the left hindlimb of a F1B control hamster. Stride frequency was significantly higher and stride length significantly shorter in TO-2 dystrophic hamsters compared to F1B control hamsters. Propulsion duration (arrows) was significantly shorter in TO-2 hamsters compared to F1B control hamsters. This finding was consistent in hamsters studied at 1 month, 3 months, and 9 months of age. (b) The relative contributions of braking and propulsion to the stance duration of forelimbs and hindlimbs in 9-month-old F1B control hamsters and TO-2 delta-sarcoglycan-deficient hamsters walking at $16 \mathrm{~cm} / \mathrm{sec}$. The relative contributions of forelimb braking and propulsion to stance were significantly altered in TO-2 dystrophic hamsters $\left({ }^{*} P<.05\right.$, TO-2 versus $\mathrm{F} 1 \mathrm{~B}$ hamsters). Although propulsion duration was decreased in TO-2 hamsters, the contribution of propulsion to stance was not different.

comparable stance durations of forelimbs $(367 \pm 8 \mathrm{~ms})$ and hindlimbs $(361 \pm 8 \mathrm{~ms})$.

3.2. Gait in Dystrophic Hamsters. Gait dynamics were significantly different in 9-month-old TO-2 dystrophic hamsters ( $n=14)$ compared to age-matched F1B control hamsters $(n=9)$ (Table 1). Figure 3(a) illustrates the gait signal from the left hindlimb of a TO-2 hamster superimposed over the gait signal of the left hindlimb of a F1B hamster. Stride frequency was increased in TO-2 compared to F1B hamsters. Stride duration was significantly shorter in TO-2 than that in F1B hamsters $(443 \pm 4 \mathrm{~ms}$ versus $503 \pm 7 \mathrm{~ms} ; P<.05)$. This was attributable to a shorter swing duration $(112 \pm 2$ versus $139 \pm 5 \mathrm{~ms} ; P<.05)$, and a shorter stance duration $(331 \pm 3 \mathrm{~ms}$ versus $364 \pm 6 \mathrm{~ms} ; P<.05)$ in TO-2 compared to F1B hamsters. Stride length was decreased in TO-2 compared to F1B hamsters $(7.1 \pm 0.1 \mathrm{~cm}$ versus $8.0 \pm 0.2 \mathrm{~cm} ; P<.05)$ at a walking speed of $16 \mathrm{~cm} / \mathrm{s}$. Forelimb stance width was narrower in TO-2 compared to F1B hamsters $(2.1 \pm 0.1 \mathrm{~cm}$ versus $2.4 \pm 0.1 \mathrm{~cm} ; P<.05)$. The paw placement angle of the hindlimbs was also more significantly everted in TO-2 than in F1B hamsters $\left(17.7 \pm 1.2^{\circ}\right.$ versus $\left.8.7 \pm 1.6^{\circ} ; P<.05\right)$. 


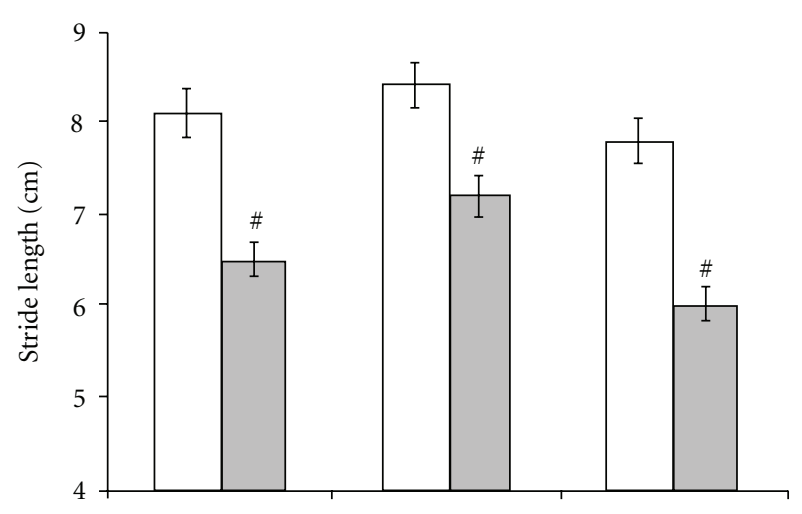

(a)
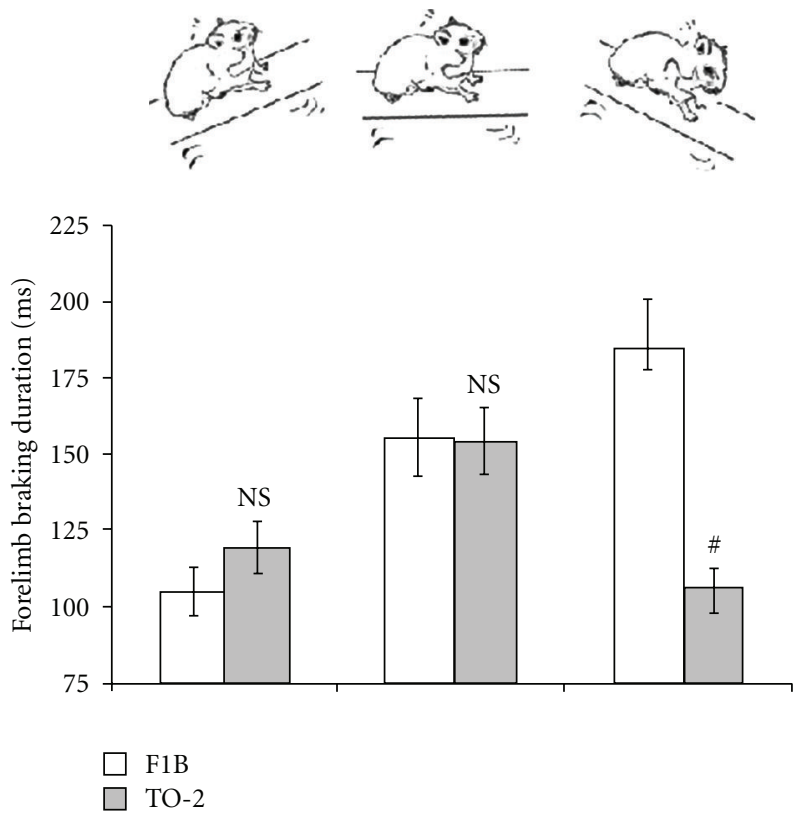

(b)

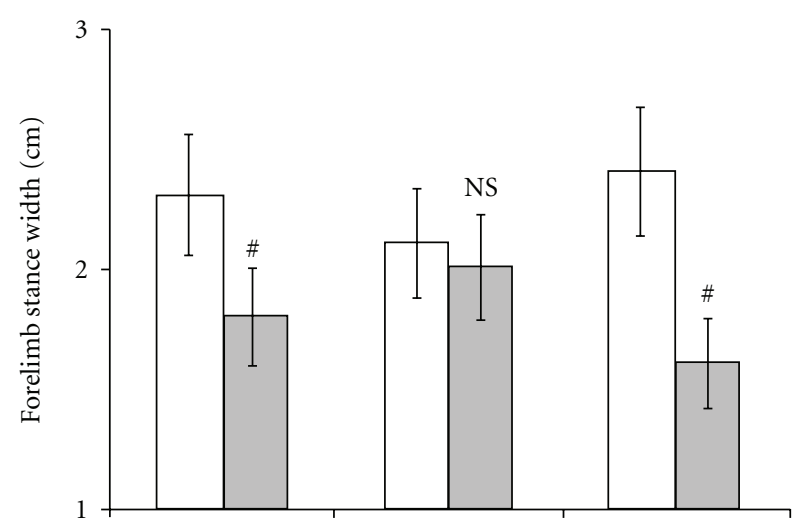

(c)
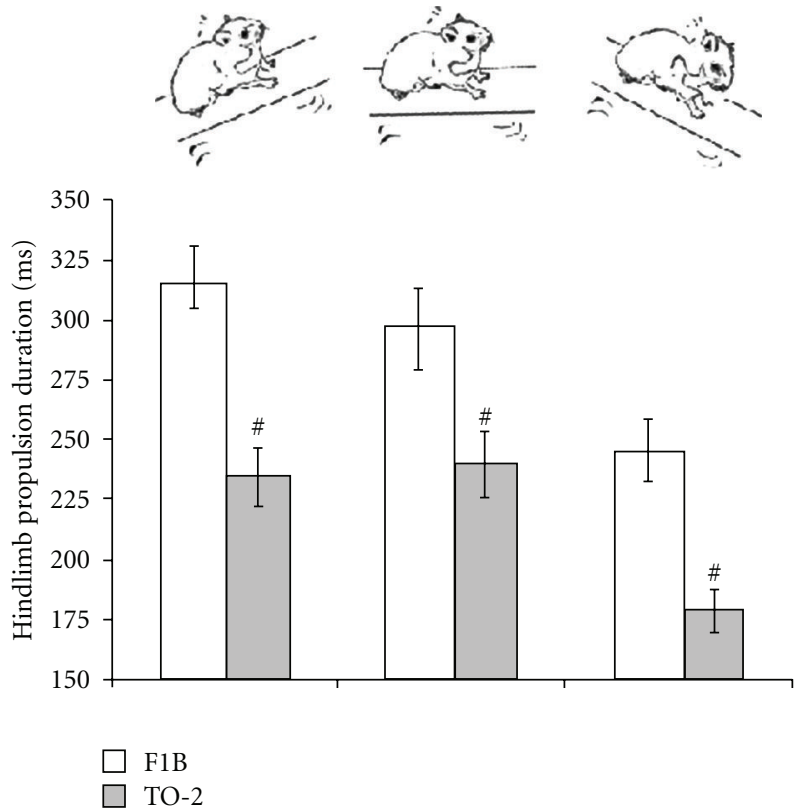

(d)

FIGURE 4: Three-month old TO-2 dystrophic hamsters exhibited significant gait differences that were consistent with those observed in 9month-old animals. (a) Stride length was shorter and (b) stance width narrower in 3-month-old TO-2 hamsters. (c) Differences in forelimb braking duration and $(\mathrm{d})$ hindlimb propulsion duration while walking horizontally [center bars] were exacerbated with uphill walking [left bars] and downhill walking [right bars]. ${ }^{\#} P<.001$ TO-2 compared to F1B.

Forelimb stride length variability was higher in TO-2 than in F1B hamsters $(23.6 \pm 1.4 \%$ versus $17.6 \pm 1.6 \% ; P<.05)$. The braking duration of the forelimbs, which is the time needed to decelerate the animal, was prolonged in TO-2 compared to F1B hamsters $(147 \pm 6 \mathrm{~ms}$ versus $126 \pm 8 \mathrm{~ms} ; P<.05)$. The propulsion duration of the hindlimbs, which reflects the interval available for force generation, was shortened in TO-2 compared to F1B hamsters $(242 \pm 7$ ms versus $272 \pm$ $11 \mathrm{~ms} ; P<.05)$ (Figure 3(a), arrows). Figure 3(b) illustrates the relative contributions of braking and propulsion to the stance duration of forelimbs and hindlimbs in 9-month-old F1B control hamsters and TO-2 delta-sarcoglycan-deficient hamsters walking at $16 \mathrm{~cm} / \mathrm{sec}$. The relative contributions of forelimb braking to stance were significantly altered in TO-2 dystrophic hamsters.
3.3. Early Functional Phenotype of Muscular Dystrophy. Most of the gait disturbances observed in 9-month-old dystrophic hamsters were also apparent at 3 months of age. Stride length was decreased in 3-month-old TO-2 dystrophic hamsters $(n=12)$ compared to F1B control hamsters $(n=6)(7.2 \pm$ $0.1 \mathrm{~cm}$ versus $8.4 \pm 0.2 \mathrm{~cm} ; P<.05)$ at a walking speed of $16 \mathrm{~cm} / \mathrm{s}$. Hindlimb stance width was narrower in TO-2 than in F1B hamsters $(3.7 \pm 0.1 \mathrm{~cm}$ versus $4.0 \pm 0.1 \mathrm{~cm} ; P<.05)$. Forelimb stance width was significantly narrower in TO-2 than in F1B hamsters when the animals were challenged to walk uphill or downhill (Figure 4). As in older animals, the paw placement angle of the 3-month-old dystrophic TO-2 hindlimbs was more significantly everted than that in F1B controls $\left(16.4 \pm 1.2^{\circ}\right.$ versus $\left.12.4 \pm 1.6^{\circ} ; P<.05\right)$. Whereas the braking duration of the forelimbs was not different in 
3-month-old TO-2 from F1B hamsters walking horizontally, the propulsion duration of the hindlimbs was shortened in 3-month-old TO-2 hamsters $(241 \pm 6 \mathrm{~ms}$ versus $298 \pm$ $9 \mathrm{~ms} ; P<.05)$. Challenging the animals to walk uphill and downhill, moreover, exacerbated functional differences between 3-month-old TO-2 $(n=4)$ and F1B hamsters $(n=4)$ (Figure 4).

Even at 1 month of age, several gait indices deviated significantly in TO-2 dystrophic hamsters. Compared to 1month-old F1B control hamsters $(n=5)$, 1-month-old TO-2 dystrophic hamsters $(n=4)$ were characterized by significantly shorter stride length $(6.6 \pm 0.1 \mathrm{~cm}$ versus $7.1 \pm$ $0.1 \mathrm{~cm})$, more eversion of the hindpaw $\left(22.4 \pm 1.8^{\circ}\right.$ versus $\left.17.9 \pm 1.8^{\circ}\right)$, shortened hindlimb propulsion duration $(125 \pm$ $5 \mathrm{~ms}$ versus $148 \pm 5 \mathrm{~ms}$ ), and prolonged forelimb braking duration $(81 \pm 3 \mathrm{~ms}$ versus $44 \pm 5 \mathrm{~ms}$ ) (all $P<.05)$. Forelimb stride length variability tended to be higher in 1-monthold TO-2 compared to F1B hamsters $(18.1 \pm 1.2 \%$ versus $15.1 \pm 1.4 \% ; P<.08)$. Figure 5 illustrates differences in stride length between F1B control and TO-2 dystrophic hamsters across the three ages studied.

\section{Discussion}

This is the first comprehensive analysis of posture and gait in hamsters, and the first quantitative analysis of gait changes in a small animal model of muscular dystrophy. Gait analysis of patients with muscular dystrophy is implemented to assess disease progression [1-3]. Mouse and hamster models are widely used to better understand and develop therapies for muscular dystrophy; yet, very little is known about how these animals walk. The postural and kinematic gait data we provide in F1B control hamsters and delta-sarcoglycandeficient TO-2 dystrophic hamsters may help to establish reference values for future studies aimed at reversing gait abnormalities with potential therapeutics tested in this animal model.

There are at least nine different types of muscular dystrophy. Loss of muscle strength is common to all types of muscular dystrophies; age of onset, muscle groups involved, and progression vary. Mutations in the sarcoglycan-gene result in limb-girdle muscular dystrophy (LGMD), of which there are different types [25]. The limb-girdle (shoulders and hips) muscles are usually the first affected, with muscle weakness becoming more progressive and spreading to more distal muscles, including tibialis anterior [26], wrists [27], and hands [28]. Delta-sarcoglycan deficiency results in LGMD-type 2F [29]. Most LGMD-type 2F patients have severe muscular dystrophy that presents early in life and progresses rapidly.

The TO-2 hamster, with a deletion in the deltasarcoglycan gene and deficiency of alpha-, beta-, and gamma-sarcoglycan, has been widely studied [16-20] and is considered a good animal model of human LGMD-type 2F. Gross examination upon autopsy of the parental strain of TO-2 hamsters indicated that shoulder muscles were the most affected [30]. Pathology has also indicated damage to the intercostal muscles, proximal limb muscles, muscles of

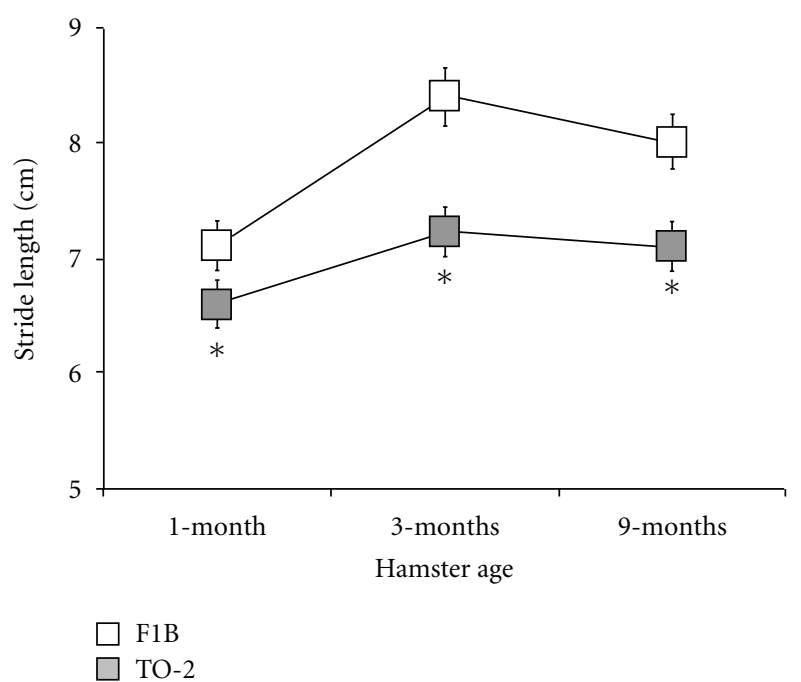

FIGURE 5: Gait disturbances were evident in TO-2 dystrophic hamsters at 1-month of age. Stride length, for example, was consistently significantly shorter in the delta-sarcoglycan-deficient dystrophic hamsters compared to F1B control hamsters at 1-month, 3-months, and 9-months of age. ${ }^{*} P<.05$, TO-2 compared to F1B.

the pelvic girdle, and muscles of the back and the abdominal wall [17]. Gastrocnemius, triceps, and tibialis muscles have also been shown to be affected [7, 16, 20, 31]. All of these muscles are involved in quadrupedal gait.

Despite extensive pathology evidence of muscle damage, very little is known about muscle dysfunction in animal models of muscular dystrophy, including the TO-2 hamster [32]. Xiao et al. demonstrated reduced tibialis anterior muscle strength in dystrophic hamsters [20]. Zhu et al. reported reduced treadmill running endurance as a measure of weakness in TO-2 hamsters [16]. Vitiello et al. concluded that gene therapy ameliorated muscular dystrophy in hamsters based on their improved rotarod performance [7]. Our treadmill gait analysis study sought to reconcile systemic muscle weakness with the ability to walk, functionality most important to patients with muscular dystrophy.

Observation of TO-2 hamsters in their cage does not suggest that they have gait disturbances, which is why we studied treadmill gait analysis in 9-month-old animals, an age of which the animals are known to have significant muscle weakness. The $\sim 13 \%$ shorter stride length in the dystrophic hamsters is a very robust deficit; in otherwise healthy patients with neuromuscular disease, $\sim 10 \%$ reductions in stride length can be clinically relevant. Because the treadmill speed was set to $16 \mathrm{~cm} / \mathrm{s}$ for both TO-2 dystrophic and F1B control animals, the shorter stride length in the TO-2 animals required significantly increased stepping frequency. Increased stepping frequency as part of daily life poses increased cardiorespiratory demands [33]. The paw placement angle of the hindlimbs was more open in TO-2 animals, suggesting weakness of muscle in the hindpaws or lower hindlimbs. Though the hindlimb propulsion duration was shorter, the percentage of contribution of the hindlimbs to propulsion was not different in TO-2 from that of F1B 
hamsters, suggesting that the shorter propulsion duration was secondary to a shorter stride cycle.

There were several important differences in forelimb gait in TO-2 dystrophic compared to F1B control hamsters. This is in contrast to some animal models of neuromuscular diseases, such as the SOD1 G93A mouse model of amyotrophic lateral sclerosis, in which the gait disturbances are more localized to the hindlimbs [11]. The forelimb stance width was significantly narrower; often, changes in base of support are compensatory to muscular and vestibular defects to maintain posture and balance. The forelimb braking duration was prolonged, but more significantly, the percentage contribution of forelimb deceleration was larger in TO-2 hamsters. Taken together, muscle weakness of the shoulder girdle and forelimbs might contribute substantively to the gait disturbances in TO-2 hamsters. This shoulder girdle functional readout is notable given that the supraspinatus muscle was the most severely affected in autopsied dystrophic hamsters [30], the relatively larger load carried by the upper limbs in quadrupeds compared to humans, and the known involvement of the shoulder girdle in LGMD patients.

The differences in gait between 3-month-old F1B and TO-2 hamsters were strikingly similar to those observed in older animals. This may not be surprising, however, since histopathology indicates extensive muscle pathology at this age $[16,17,19,31,34]$. Challenging the animals to incline or decline walking exacerbated postural and kinematic differences. Downhill walking especially increased the magnitude of differences in stride length, stance width, and propulsion duration. Walking up an incline or down a decline is known to changes muscle load and force distribution $[35,36]$; this is especially true for quadrupeds that use their forelimbs for weight support. Downhill walking has been shown to increase loading on the shoulders and upper limbs of pongids [37], cats [36], and rats [38]. Shoulder muscles are particularly vulnerable in LGMD. The observations of exacerbated upper limb gait disturbances in the TO-2 hamsters downhill walking suggest that the shoulder girdle may be more affected, at least functionally, than the hip girdle in the delta-sarcoglycan-deficient hamster model of muscular dystrophy.

Skeletal muscle pathology is already evident in TO-2 animals one month old $[17,19,30,34]$. We observed significant differences in posture and gait between 1-monthold TO-2 dystrophic and F1B control hamsters. Several metrics, including shorter stride length and greater hindpaw eversion, were consistent findings in juvenile (1-monthold), young (3-month-old), and adult (9-month-old) deltasarcoglycan-deficient dystrophic hamsters. In summary, gait analysis in delta-sarcoglycan-deficient dystrophic BIO TO-2 hamsters provides early functional evidence of systemic muscle weakness that could accelerate the screening of potential therapies for muscular dystrophy.

\section{Disclosure}

T. G. Hampton is owner of Mouse Specifics, Inc., a company that has commercialized the gait analysis instrumentation.
C. G. VanDongen. is owner of BioBreeders, Inc., a purveyor of hamsters.

\section{Acknowledgments}

This paper is dedicated to the memory of Dr. Ivo Amende, a clinician and scholar who readily translated animal research to the clinics, and taught the authors much about human nature. Cecelia Hampton is acknowledged for her helpful comments on the manuscript.

\section{References}

[1] S. Khodadadeh, M. R. McClelland, and J. H. Patrick, "Variations of gait parameters in Duchenne muscular dystrophy," Proceedings of the Institution of Mechanical Engineers, Part H, vol. 204, no. 4, pp. 241-243, 1990.

[2] N. Gaudreault, D. Gravel, S. Nadeau, S. Houde, and D. Gagnon, "Gait patterns comparison of children with Duchenne muscular dystrophy to those of control subjects considering the effect of gait velocity," Gait and Posture, vol. 32, no. 3, p. 342, 2010.

[3] S. Sienko Thomas, C. E. Buckon, A. Nicorici, A. Bagley, C. M. McDonald, and M. D. Sussman, "Classification of the gait patterns of boys with Duchenne muscular dystrophy and their relationship to function," Journal of Child Neurology, vol. 25, no. 9, pp. 1103-1109, 2010.

[4] K. E. Wells and D. J. Wells, "What do animal models have to tell us regarding Duchenne muscular dystrophy?" Acta Myologica, vol. 24, no. 3, pp. 172-180, 2005.

[5] S. Goudenege, Y. Lamarre, N. Dumont et al., "Laminin111: a potential therapeutic agent for Duchenne muscular dystrophy," Molecular Therapy, vol. 18, no. 12, pp. 2155-2163, 2010.

[6] G. L. Odom, P. Gregorevic, J. M. Allen, E. Finn, and J. S. Chamberlain, "Microutrophin delivery through rAAV6 increases lifespan and improves muscle function in dystrophic dystrophin/Utrophin-deficient mice," Molecular Therapy, vol. 16, no. 9, pp. 1539-1545, 2008.

[7] C. Vitiello, S. Faraso, N. C. Sorrentino et al., "Disease rescue and increased lifespan in a model of cardiomyopathy and muscular dystrophy by combined AAV treatments," PLoS ONE, vol. 4, no. 3, Article ID e5051, 2009.

[8] N. P. Whitehead, M. Streamer, L. I. Lusambili, F. Sachs, and D. G. Allen, "Streptomycin reduces stretch-induced membrane permeability in muscles from $\mathrm{mdx}$ mice," Neuromuscular Disorders, vol. 16, no. 12, pp. 845-854, 2006.

[9] K. Nagaraju and R. Willmann, "Developing standard procedures for murine and canine efficacy studies of DMD therapeutics: report of two expert workshops on "Pre-clinical testing for Duchenne dystrophy": Washington DC, October 27th-28th 2007 and Zürich, June 30th-July 1st 2008," Neuromuscular Disorders, vol. 19, no. 7, pp. 502-506, 2009.

[10] A. P. Marsh, J. D. Eggebeen, J. N. Kornegay, C. D. Markert, and M. K. Childers, "Kinematics of gait in Golden Retriever Muscular Dystrophy," Neuromuscular Disorders, vol. 20, no. 1, pp. 16-20, 2010.

[11] T. G. Hampton and I. Amende, "Treadmill gait analysis characterizes gait alterations in parkinson's disease and amyotrophic lateral sclerosis mouse models," Journal of Motor Behavior, vol. 42, no. 1, pp. 1-4, 2009. 
[12] Y.-F. Xu, T. F. Gendron, Y.-J. Zhang et al., "Wild-type human TDP-43 expression causes TDP-43 phosphorylation, mitochondrial aggregation, motor deficits, and early mortality in transgenic mice," Journal of Neuroscience, vol. 30, no. 32, pp. 10851-10859, 2010.

[13] J. E. Springer, R. R. Rao, H. R. Lim et al., "The functional and neuroprotective actions of Neu2000, a dual-acting pharmacological agent, in the treatment of acute spinal cord injury," Journal of Neurotrauma, vol. 27, no. 1, pp. 139-149, 2010.

[14] W. C. Huang, W. C. Kuo, S. H. Hsu, C. H. Cheng, J. C. Liu, and H. Cheng, "Gait analysis of spinal cord injured rats after delivery of chondroitinase $\mathrm{ABC}$ and adult olfactory mucosa progenitor cell transplantation," Neuroscience Letters, vol. 472, no. 2, pp. 79-84, 2010.

[15] S. Tashman, W. Anderst, P. Kolowich, S. Havstad, and S. Arnoczky, "Kinematics of the ACL-deficient canine knee during gait: serial changes over two years," Journal of Orthopaedic Research, vol. 22, no. 5, pp. 931-941, 2004.

[16] T. Zhu, L. Zhou, S. Mori et al., "Sustained whole-body functional rescue in congestive heart failure and muscular dystrophy hamsters by systemic gene transfer," Circulation, vol. 112, no. 17, pp. 2650-2659, 2005.

[17] V. Straub, F. Duclos, D. P. Venzke et al., "Molecular pathogenesis of muscle degeneration in the $\delta$-sarcoglycan- deficient hamster," American Journal of Pathology, vol. 153, no. 5, pp. 1623-1630, 1998.

[18] Y. Mizuno, S. Noguchi, H. Yamamoto et al., "Sarcoglycan complex is selectively lost in dystrophic hamster muscle," American Journal of Pathology, vol. 146, no. 2, pp. 530-536, 1995.

[19] Y. Kato, M. Iwase, K. Takagi et al., "Differential myolysis of myocardium and skeletal muscle in hamsters with dilated cardiomyopathy-beneficial protective effect of diltiazem," Circulation Journal, vol. 70, no. 11, pp. 1497-1502, 2006.

[20] X. Xiao, J. Li, Y. P. Tsao, D. Dressman, E. P. Hoffman, and J. F. Watchko, "Full functional rescue of a complete muscle (TA) in dystrophic hamsters by adeno-associated virus vector-directed gene therapy," Journal of Virology, vol. 74, no. 3, pp. 1436$1442,2000$.

[21] T. G. Hampton, M. R. Stasko, A. Kale, I. Amende, and A. C. S. Costa, "Gait dynamics in trisomic mice: quantitative neurological traits of Down syndrome," Physiology and Behavior, vol. 82, no. 2-3, pp. 381-389, 2004.

[22] A. Kale, I. Amende, G. P. Meyer, J. C. Crabbe, and T. G. Hampton, "Ethanol's effects on gait dynamics in mice investigated by ventral plane videography," Alcoholism, vol. 28, no. 12, pp. 1839-1848, 2004.

[23] F. P. T. Hamers, A. J. Lankhorst, T. J. Van Laar, W. B. Veldhuis, and W. H. Gispen, "Automated quantitative gait analysis during overground locomotion in the rat: its application to spinal cord contusion and transection injuries," Journal of Neurotrauma, vol. 18, no. 2, pp. 187-201, 2001.

[24] V. Brussee, F. Tardif, and J. P. Tremblay, "Muscle fibers of mdx mice are more vulnerable to exercise than those of normal mice," Neuromuscular Disorders, vol. 7, no. 8, pp. 487-492, 1997.

[25] L. E. Lim and K. P. Campbell, "The sarcoglycan complex in limb-girdle muscular dystrophy," Current Opinion in Neurology, vol. 11, no. 5, pp. 443-452, 1998.

[26] A. Y. Belanger and A. J. McComas, "Neuromuscular function in limb girdle dystrophy," Journal of Neurology Neurosurgery and Psychiatry, vol. 48, no. 12, pp. 1253-1258, 1985.
[27] G. P. Hosking, U. S. Bhat, V. Dubowitz, and R. H. T. Edwards, "Measurements of muscle strength and performance in children with normal and diseased muscle," Archives of Disease in Childhood, vol. 51, no. 12, pp. 957-963, 1976.

[28] G. P. Hosking, A. Young, V. Dubowitz, and R. H. T. Edwards, "Tests of skeletal muscle function in children," Archives of Disease in Childhood, vol. 53, no. 3, pp. 224-229, 1978.

[29] V. Nigro, E. De Sá Moreira, G. Piluso et al., "Autosomal recessive limb-girdle muscular dystrophy, LGMD2F, is caused by a mutation in the $\delta$-sarcoglycan gene," Nature Genetics, vol. 14, no. 2, pp. 195-198, 1996.

[30] F. Homburger, "Myopathy of hamster dystrophy: history and morphologic aspects," Annals of the New York Academy of Sciences, vol. 317, pp. 1-17, 1979.

[31] J. Li, D. Dressman, Y. P. Tsao, A. Sakamoto, E. P. Hoffman, and X. Xiao, "rAAV vector-mediated sarcogylcan gene transfer in a hamster model for limb girdle muscular dystrophy," Gene Therapy, vol. 6, no. 1, pp. 74-82, 1999.

[32] J. F. Watchko, T. L. O’Day, and E. P. Hoffman, "Functional characteristics of dystrophic skeletal muscle: insights from animal models," Journal of Applied Physiology, vol. 93, no. 2, pp. 407-417, 2002.

[33] S. H. Loring, J. Mead, and T. B. Waggener, "Determinants of breathing frequency during walking," Respiration Physiology, vol. 82, no. 2, pp. 177-188, 1990.

[34] K. H. Holt, L. E. Lim, V. Straub et al., "Functional rescue of the sarcoglycan complex in the BIO 14.6 hamster using $\delta$-sarcoglycan gene transfer," Molecular Cell, vol. 1, no. 6, pp. 841-848, 1998.

[35] P. Carlson-Kuhta, T. V. Trank, and J. L. Smith, "Forms of forward quadrupedal locomotion. II. A comparison of posture, hindlimb kinematics, and motor patterns for upslope and level walking," Journal of Neurophysiology, vol. 79, no. 4, pp. 1687-1701, 1998.

[36] J. L. Smith, P. Carlson-Kuhta, and T. V. Trank, "Forms of forward quadrupedal locomotion. III. A comparison of posture, hindlimb kinematics, and motor patterns for downslope and level walking," Journal of Neurophysiology, vol. 79, no. 4, pp. 1702-1716, 1998.

[37] R. H. Tuttle and J. V. Basmajian, "Electromyography of pongid shoulder muscles. III. Quadrupedal positional behavior," American Journal of Physical Anthropology, vol. 49, no. 1, pp. 57-70, 1978.

[38] A. Scott, J. L. Cook, D. A. Hart, D. C. Walker, V. Duronio, and K. M. Khan, "Tenocyte responses to mechanical loading in vivo: a role for local insulin-like growth factor 1 signaling in early tendinosis in rats," Arthritis and Rheumatism, vol. 56, no. 3, pp. 871-881, 2007. 


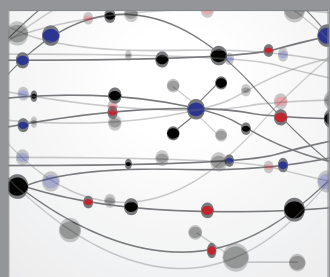

The Scientific World Journal
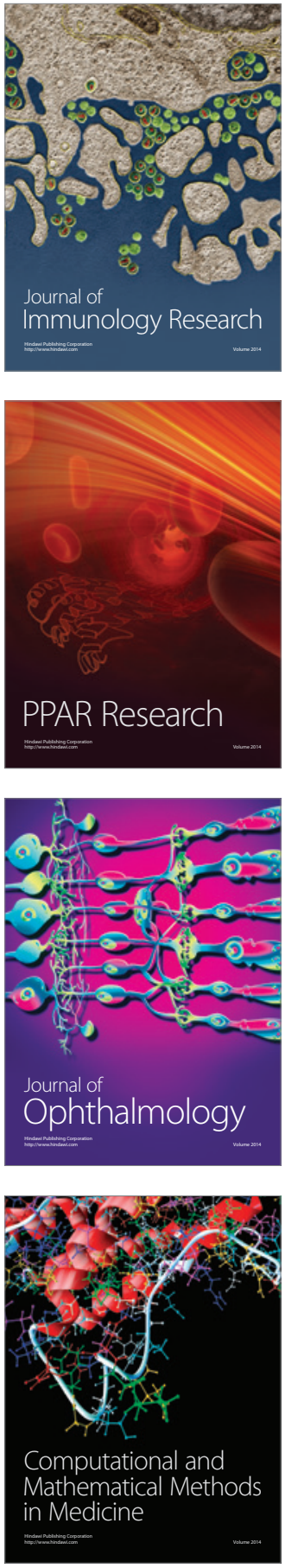

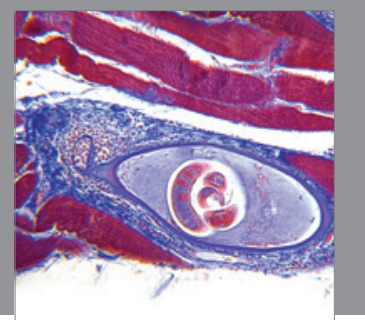

Gastroenterology

Research and Practice
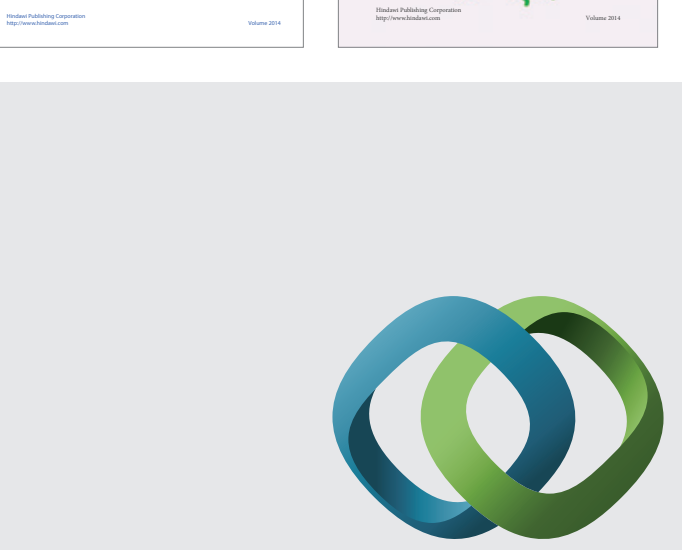

\section{Hindawi}

Submit your manuscripts at

http://www.hindawi.com
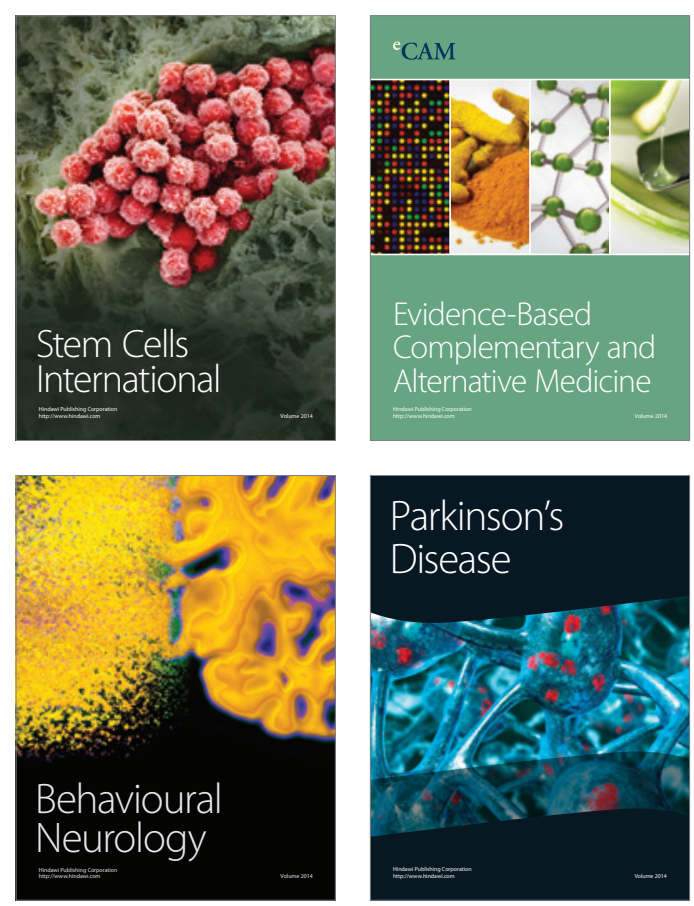

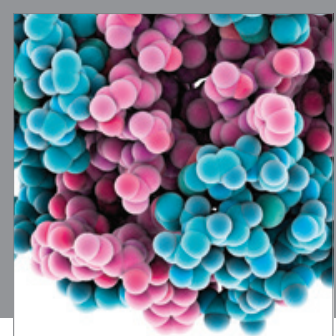

Journal of
Diabetes Research

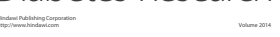

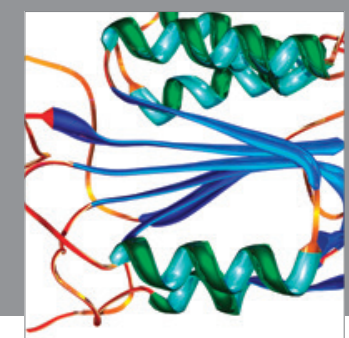

Disease Markers
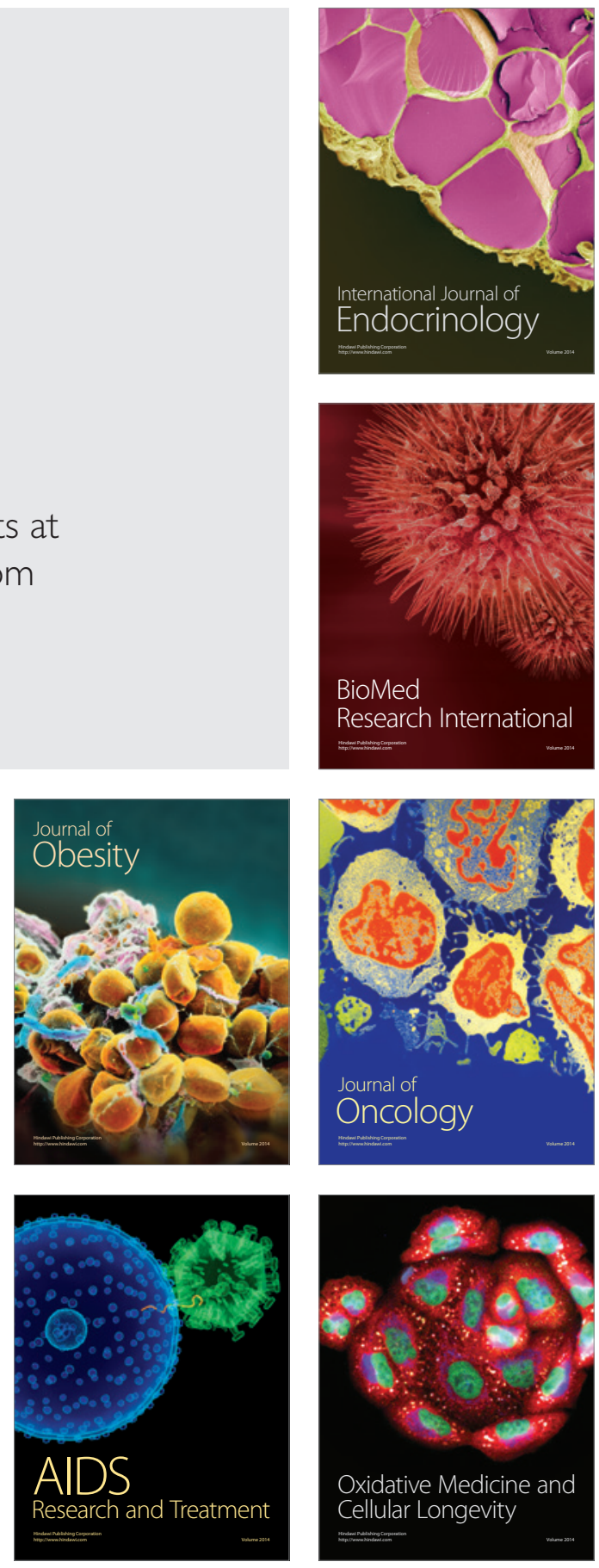